returned to normal; this took from 17 to 35 days (mean $26 \pm 4.0$ ) after injury or surgery.

Discussion. Although our series documents a high prevalence of extreme thrombocytosis following orthopaedic surgery, no patient had severe thrombosis or bleeding. Buss, Stuart and Lipscomb (1985) reported that of 129 patients with platelet counts greater than $1 \times 10^{6} /$ $\mathrm{mm}^{3}$ only seven followed surgery, and all of these were after splenectomy. Our finding of seven patients with extreme thrombocytosis in only 200 admissions is surprisingly high. Alcoholism is probably the strongest risk factor after orthopaedic surgery. Although we did not determine the incidence of alcoholism in the patients without extreme thrombocytosis, Schnitzler et al (1988), reported an incidence of only $20.4 \%$ in a similar population. That thrombocytosis develops in alcoholic patients when alcohol is withdrawn has been previously reported (Lindenbaum and Hargrove 1968), but the peak counts do not reach extreme levels. It is possible that the expected thrombocytosis which occurs after orthopaedic surgery has a synergistic effect with withdrawal of alcohol, producing extreme levels. The patient with acute diverticulitis who also developed extreme thrombocytosis suggests that other inflammatory or infectious diseases which are commonly associated with thrombocytosis may exert a similar synergism.

It is doubtful whether these findings are unique to orthopaedic surgery; probably they occur because orthopaedic surgeons frequently operate on alcoholic patients and when extreme thrombocytosis occurs in this setting it should suggest an underlying disorder, especially alcoholism.

No benefits in any form have been received or will be received from a commercial party related directly or indirectly to the subject of this article.

\section{REFERENCES}

Buss DH, Stuart JJ, Lipscomb GE. The incidence of thrombotic and hemorrhagic disorders in association with extreme thrombocytosis: an analysis of 129 cases. Am J Hematol 1985; 20:365-72.

Lindenbaum J, Hargrove RL. Thrombocytopenia in alcoholics. Ann Int Med 1968; 68:526-32.

Schnitzler CM, Menashe L, Sutton CG, Sweet MB. Serum biochemical and haematological markers of alcohol abuse in patients with femoral neck and intertrochanteric fractures. Alcohol Alcohol 1988; 23:127-32.

Williams JA, Warren R. Endocrine factors in the alterations of the blood coagulation mechanism following surgery. $J$ Lab Clin Med 1957; 50:372-75.

\title{
THE RAPID ASSESSMENT OF NERVE STUMPS
}

\author{
S. E. GSCHMEISSNER, J. H. PEREIRA, S. A. COWLEY
}

The secondary repair or grafting of damaged nerves has a very variable prognosis. One of the most important factors is the quality of nerve tissue at the site of the repair. This is normally assessed by the naked eye and magnified appearance of the nerve after resection of the neuroma, distal glioma or length of nerve affected by a traction injury. This is a difficult assessment even in experienced hands (Birch et al 1986) and the histological study of resected stumps from such operations has shown that there is often a discrepancy between the macroscopic appearance and the histological findings.

We have developed a method for the rapid frozen section assessment of the quality of nerve stumps at operation, and have applied it to specimens from normal

S. E. Gschmeissner, BSc, Chief Scientific Officer

Electronmicroscopic Unit, Imperial Cancer Research Fund, Lincoln's Inn Fields, London WC2A 3PX, England.

J. H. Pereira, FRCS, Bernard Sunley Research Fellow, Department of Anatomy

S. A. Cowley, PhD, Department of Pathology

Royal College of Surgeons of England, 35-43 Lincoln's Inn Fields, London WC2A 3PN, England.

Correspondence to Mr J. H. Pereira.

(C) 1991 British Editorial Society of Bone and Joint Surgery 0301-620X/91/4R21 \$2.00

J Bone Joint Surg [Br] 1991 ; 73-B: 688-9. nerve, delayed repair, traction injury and nerves affected by leprosy.

Method. The fresh specimen is frozen; $7 \mu \mathrm{m}$ sections are made, mounted on a slide and stained with osmium tetroxide for 30 seconds. They are then washed in several changes of distilled water and covered with freshly prepared $1 \%$ paraphenylene diamine for a further 30 seconds. After more washes in distilled water the section is mourted directly in an aqueous mountant for inspection. The depth of staining can be adjusted by changing the time in osmium; undue contamination with fat can be avoided where necessary by an acetone wash before the osmium tetroxide staining.

Results. Myelin is stained dark brown. All other tissue elements are stained only weakly. Normal nerve shows even, dense staining of axons of varying sizes throughout the nerve (Fig. 1). A nerve which has suffered a mild traction injury shows a relatively more diffuse distribution of stained axons while, after a severe traction injury, stained axons are small and scarce. Comparison of Figures 1, 2 and 3, all from the same patient, show the varying degrees of intrafunicular damage which can be detected. Figure 4 is a section from a neuroma showing complete disorientation of myelinated axons.

Discussion. The frozen section technique that we describe takes about two minutes. It provides consistently good 


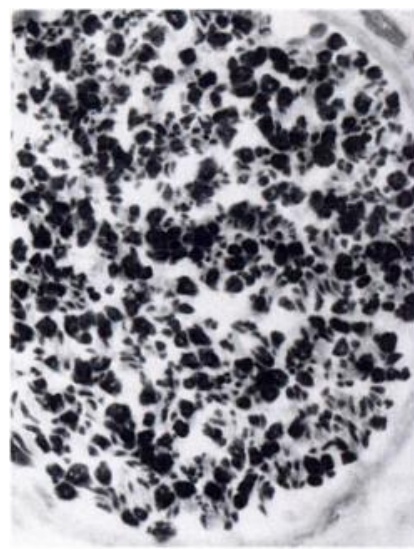

Fig. 1

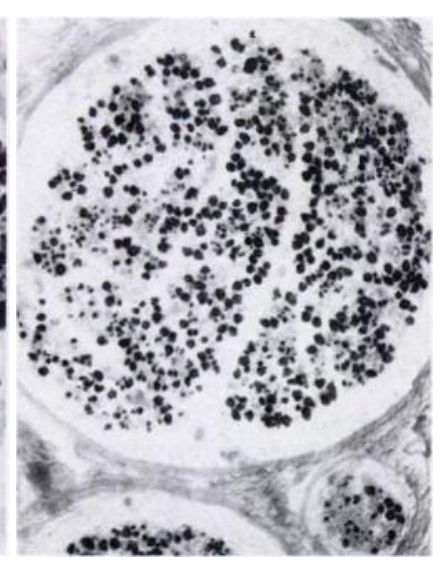

Fig. 2

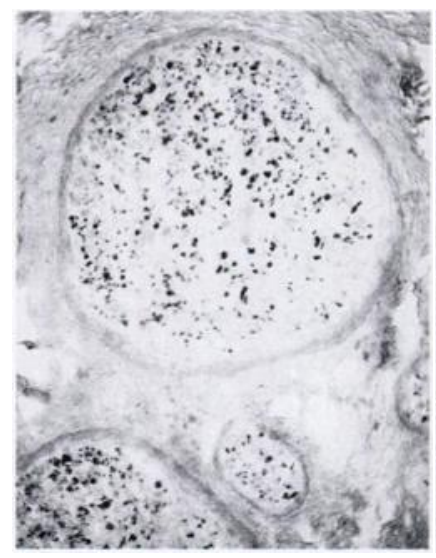

Fig. 3

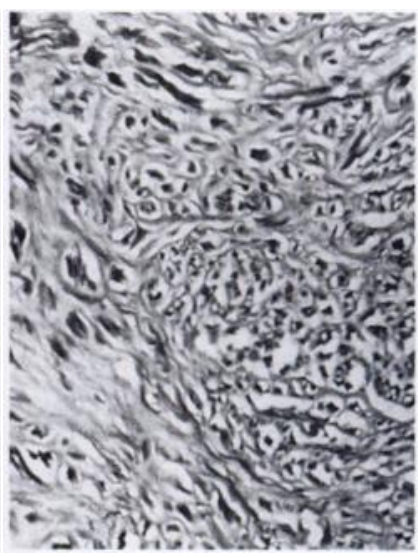

Fig. 4

Frozen sections at $\times 60$. Figure $1-$ Normal intercostal nerve. Figure $2-$ Mild traction injury, superficial radial nerve. Figure 3 - Severe traction injury, median nerve. Figure 4 - Neuroma.

sections allowing both quantitative and qualitative assessment of myelinated fibres in proximal and distal stumps. Frozen section study has been attempted previously (Mackenzie and Wood 1961) but was unsuccessful because of lack of intrafunicular details (Seddon 1975).

The rationale of our method is not understood fully, but Estable-Piug, Bauer and Blumberg (1965) suggest that paraphenylene diamine produces highly coloured reduction products in the presence of osmium. We have found this technique useful in the operating theatre, enabling us to obtain much better quality nerve stumps at the time of repair. We are now investigating the use of this stain in the assessment of nerves damaged by leprosy and of nerve tumours.
This work is supported by the Bernard Sunley Research Foundation. The authors would like to express their thanks to Mr R. W. Norris, FRCS; Mr R. Birch, FRCS; and Dr D. D. Palande, MS, for providing us with the nerve specimens. We are also grateful to Mr George Elia for skilled technical help.

No benefits in any form have been received or will be received from a commercial party related directly or indirectly to the subject of this article.

\section{REFERENCES}

Birch R, Bonney G, Payan J, Wynn Parry CB, Iggo A. Peripheral nerve injuries. J Bone Joint Surg [Br] 1986; 68-B:2-21.

Estable-Piug JF, Bauer WC, Blumberg JM. Paraphenylenediamine staining of osmium-fixed plastic-embedded tissue for light and phase microscopy. J Neuropath Exp Neurol 1965; 24:531-5.

Mackenzie IG, Wood CG. Causes of failure after repair of median nerve. J Bone Joint Surg [Br] 1961 ; 43-B:465-73.

Seddon H. Surgical disorders of the peripheral nerves. 2nd ed. Edinburgh, etc: Churchill Livingstone, 1975.

\section{CONTRALATERAL SCIATIC NERVE PALSY FOLLOWING FEMORAL NAILING}

\section{G. R. TAIT, M. DANTON}

Two cases of contralateral sciatic nerve palsy following closed femoral nailing are described. The influence of the position of the non-operated leg during a prolonged procedure is discussed.

Case 1. A 55-year-old man fell from a ladder sustaining a spiral fracture of the mid-shaft and a basal fracture of the neck of the right femur. The fractures were fixed using a Richards Recon femoral nail inserted closed. During the operation the patient was on a fracture table

G. R. Tait, FRCS G, Senior Orthopaedic Registrar M. Danton, MB, ChB, BAO, Senior House Officer

Department of Orthopaedic Surgery, Belfast City Hospital, Lisburn Road, Belfast BT9 7AB, Northern Ireland.

Correspondence to Mr G. R. Tait at the Department of Orthopaedic Surgery, Victoria Infirmary, Langside, Glasgow G42 9TY, Scotland.

(C) 1991 British Editorial Society of Bone and Joint Surgery

$0301-620 X / 91 / 4 R 22 \$ 2.00$

J Bone Joint Surg [Br] 1991 ; 73-B : 689-90. with the injured leg extended. To facilitate radiographic visualisation of the upper femoral shaft, the other leg was suspended by the foot from a drip stand attached to the operating table, with the hip and knee each flexed to about $90^{\circ}$, in the hemilithotomy position. The total operating time was 2.5 hours and the operation itself was uneventful.

Next morning the patient complained of a numb left leg and was found to have a drop-foot which was insensitive. There was no evidence of local injury to the common peroneal nerve. Over the next 72 hours both the numbness and the drop-foot resolved. He mobilised very well and was discharged home 10 days later walking with crutches. There were no residual sciatic nerve symptoms. Case 2. A 23-year-old man suffered a comminuted fracture of the shaft of the right femur in a motor-cycle accident. The fracture was fixed closed, using a locked nail. To facilitate radiography the opposite leg was 